\title{
Kontrol Tegangan Self-Excited Induction Generator dengan Electronic Load Controller Terkontrol PID-GA
}

\author{
Ermanu Azizul Hakim*1, Rahayu Pandunengsih ${ }^{2}$, Diding Suhardi ${ }^{3}$, Novendra Setyawan ${ }^{4}$ \\ 1,2,3,4 Teknik Elektro, Universitas Muhammadiyah Malang, Indonesia \\ e-mail: *21 ermanu@umm.ac.id, ${ }^{2}$ rpandunengsih@gmail.com, ${ }^{3}$ diding@umm.ac.id \\ novendra@umm.ac.id
}

\begin{abstract}
Abstrak
Generator induksi dalam operasinya memerlukan daya reaktif yang harus diumpankan secara eksternal. Salah satu jenis generator induksi yaitu SEIG daya reaktifnya dipasok oleh bank kapasitor yang terhubung di terminal generator. SEIG banyak diminati untuk konversi energi di area terpencil, namun SEIG memiliki kelemahan utama yaitu pengaturan tegangan yang buruk dalam berbagai kondisi beban. Untuk mengatasi masalah tersebut digunakanlah ELC dengan kontrol PID yang dioptimasi menggunakan algoritma genetika agar dapat menjaga kestabilan tegangan ketika beban bervariasi. Hasil pengujian menunjukkan sistem SEIG menggunakan ELC dengan kontrol PID-GA dapat menjaga tegangan stabil sesuai standar dengan toleransi tegangan sebesar $10 \%$ ketika terjadi perubahan beban. Penambahan GA untuk menentukan nilai parameter PID menghasilkan respon yang lebih baik dengan selisih nilai overshoot ketika start awal sebesar 70,48\%, ketika terjadi penurunan beban di detik ke-5 sebesar 44,3\% dan di detik ke-10 saat terdapat kenaikan beban sebesar $2 \mathrm{~kW}$ memiliki selisih 5,96\% dibandingkan sistem dengan kontrol PID tanpa optimasi GA.
\end{abstract}

Kata kunci-Kontrol Tegangan, Generator Induksi Bereksitasi Mandiri, Pengontrol Beban Elektronik, Algoritma Genetika

\begin{abstract}
Induction generator operation requires reactive power with external contactor. One of induction generator types, SEIG reactive power supplied by capacitor bank connected to generator terminal. SEIG is alternative energy conversion in small area or rural, SEIG has the main disadvantage of poor voltage regulation under various load conditions. ELC combine PID control which is optimized using Genetic Algorithm in order to maintain the stability of the voltage when the load varies. The result shows the SEIG system using ELC with PID-GA control worked to stable voltage in accordance with the standard with voltage tolerance of $10 \%$ when load change. The addition of GA to determine the value of the PID parameter where response system better with difference overshoot value start is $70.48 \%$, when decrease load in 5 second by $44.3 \%$ and in the 10 second when increase load of $2 \mathrm{~kW}$ is $5.96 \%$ compared system with PID control without GA optimization.
\end{abstract}

Keywords - Voltage Control, Self-Excited Induction Generator, Electronic Load Controller, Genetic Algorithm.

\section{PENDAHULUAN}

Generator induksi akhir-akhir ini semakin banyak digunakan karena memiliki fitur yang relative lebih menguntungkan dibandingkan jenis generator lain. Untuk operasinya, generator induksi memerlukan daya reaktif yang harus diumpankan secara eksternal. Dalam aplikasinya generator induksi terbagi dua jenis, yaitu Doubly Fed Induction Generator (DFIG) dan SelfExcited Induction Generator (SEIG). Pada SEIG, daya reaktifnya dipasok oleh bank kapasitor 
yang terhubung di terminal generator [1]. Untuk konversi energy di area terpencil yang terisolasi SEIG lebih diminati. Namun kelemahan utama dari SEIG adalah pengaturan tegangan dan frekuensi yang buruk dalam berbagai kondisi beban, sehingga dibutuhkan sistem yang dapat mempertahankan tegangan agar tetap konstan pada beban bervariasi. Biasanya, Electronic Load Controller (ELC) merupakan perangkat yang digunakan untuk masalah tersebut [2][3]. Electronic Load Controller (ELC) merupakan sistem sederhana yang terdiri dari sistem rectifier dan chopper tidak terkontrol dengan beban dump. Daya dalam beban dump dikontrol melalui duty cycle pada chopper untuk menjaga daya tetap konstan.

Penelitian sebelumnya [4], dilakukan analisis dan desain ELC untuk SEIG yang cocok untuk pembangkit listrik bersistem stand-alone dengan daya input konstan. ELC yang diusulkan terdiri dari rectifier dan chopper yang tidak terkontrol dengan beban dump seri. Prosedur desain untuk menghitung nilai berbagai komponen ELC juga disajikan untuk berbagai SEIG. Dan disimpulkan bahwa ELC SEIG yang dikembangkan dapat mempertahankan tegangan konstan pada frekuensi konstan meskipun ada variasi beban konsumen. Namun dalam penelitian tersebut ELC belum dilengkapi dengan suatu teknik pengontrolan. Sedangkan dalam penelitian [2], mengontrol tegangan dan frekuensi pada SEIG agar tetap konstan dengan menggunakan ELC. Hasilnya, dengan menggunakan ELC pada SEIG tegangan dan frekuensi dapat konstan walaupun terjadi perubahan beban. Namun disini hanya menggunakan kontroler PID, belum menggunakan teknik pengontrolan PID dengan menggunakan tuning algoritma untuk menentukan nilai $K_{p}, K_{\mathrm{i}}$, dan $K_{d}$.

Performansi dari penelitian sebelumnya dapat ditingkatkan lagi dengan cara menambahkan algoritma heuristik untuk tuning nilai PID. Beberapa algoritma heuristic yang telah diimplementasikan diantaranya PSO [5][6], Jaya-Algorithm [7], dan Genetic Algorithm (GA) [8]. Pada penelitian ini akan menambahkan GA sebagai alternative metode dalam meningkatkan performansi ELC demi mempertahankan tegangan keluaran SEIG tetap konstan walaupun beban bervariasi. Metode ini dipilih karena algoritma genetika banyak dipergunakan untuk menyelesaikan permasalahan optimasi. Kontroler algoritma genetika memiliki overshoot minimum, sehingga penggunaan algoritma genetika dapat menunjukkan performa yang baik dalam berbagai kondisi.

\section{METODE PENELITIAN}

Sistem kontrol tegangan Self-Excited Induction Generator (SEIG) menggunakan algoritma genetika secara umum dapat dilihat pada Gambar 1. Terdiri dari generator induksi, beban komplemen, beban konsumen dan sistem kontrol tegangan. SEIG tiga fase dihubungkan secara delta yang digerakkan oleh prime mover dengan nilai konstan. Bank kapasitor digunakan sebagai penyuplai daya reaktif generator yang dipasang pada terminal keluaran SEIG dengan terhubung delta. Daya yang dibutuhkan oleh beban konsumen suatu saat akan berubah-ubah. Saat itu terjadi, maka ELC akan mengalihkan kelebihan daya tersebut ke beban dump. Namun saat tidak terdapat kelebihan daya, maka tidak ada pengalihan beban ke beban dump. Algoritma genetika digunakan untuk tuning nilai PID dalam mengatasi fluktuasi tegangan karena perubahan beban, output dari generator ke konsumen akan disensor oleh sebuah sensor tegangan dan di umpan balikkan ke set point sebagai nilai error. Nilai error akan menjadi input dari controller PID.

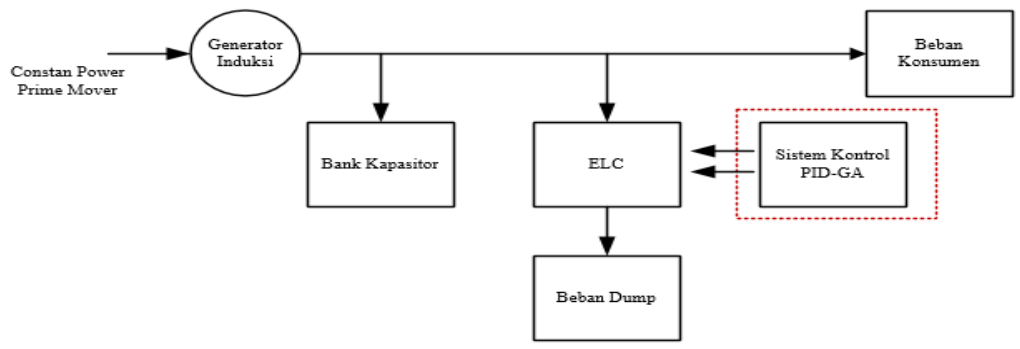

Gambar 1. Skema Perancangan Sistem Kontrol Tegangan

IJEIS Vol. 10, No. 1, April 2020 : 41-52 


\subsection{Model Generator}

Pemodelan generator berkapasitas $7.5 \mathrm{~kW}$ yang digunakan adalah mesin induksi yang dioperasikan sebagai generator. Data yang ditetapkan sebagai nilai parameter generator induksi pada penelitian ini merupakan data dari MATLAB. Tabel 1 adalah parameter generator induksi yang digunakan.

Tabel 1 Parameter Generator Induksi

\begin{tabular}{|l|c|}
\hline \multicolumn{1}{|c|}{ Parameter } & Value \\
\hline Nominal Power $(\mathrm{kW})$ & 7.5 \\
\hline Voltage (line-to-line) $(\mathrm{V})$ & 400 \\
\hline Frequency $(\mathrm{Hz})$ & 50 \\
\hline Stator resistance $(\mathrm{ohm})$ & 0.7384 \\
\hline Rotor resistance $(\mathrm{ohm})$ & 0.7402 \\
\hline Stator inductance $(\mathrm{H})$ & 0.003045 \\
\hline Rotor inductance $(\mathrm{H})$ & 0.003045 \\
\hline Mutual inductance $(\mathrm{H})$ & 0.1241 \\
\hline Inertia $\left(\mathrm{kg} \cdot \mathrm{m}^{2}\right)$ & 0.0343 \\
\hline Friction factor $(\mathrm{N} . \mathrm{m} . \mathrm{s})$ & 0.000503 \\
\hline Pole pairs & 2 \\
\hline
\end{tabular}

\subsection{Kapasitor Bank}

Kapasitor eksitasi yang digunakan adalah kapasitor tiga fasa yang terhubung delta. Kapasitor eksitasi yang digunakan akan bernilai tetap saat simulasi dilakukan. Setelah dilakukan perhitungan [9], besar nilai eksitasi minimum tersebut digunakan dalam simulasi, namun nilai tersebut belum dapat mencukupi daya rektif yang dibutuhkan oleh generator induksi. Untuk menyelaraskan reaktansi magnetic, maka penetapan nilai kapasior eksitasi dilakukan dengan menggunakan metode trial and error ditunjukkan dalam Tabel 2. Sehingga pada sistem generator induksi 3 fasa dengan beban $6 \mathrm{~kW}$ didapat nilai kapasitor eksitasi yang sesuai yaitu sebesar 3700 Var.

Tabel 2. Penentuan Nilai Kapasitor Beban 6 kW

\begin{tabular}{|c|c|c|}
\hline $\begin{array}{c}\text { Kapasitor } \\
\text { Eksitasi (Var) }\end{array}$ & $\begin{array}{c}\text { Tegangan } \\
\text { RMS (Volt) }\end{array}$ & Keterangan \\
\hline 1500 & 503 & Vrms tinggi, > 400 Volt \\
\hline 2500 & 421 & Vrms tinggi, > 400 Volt \\
\hline 3700 & 395 & Vrms mendekati 400 Volt \\
\hline 5700 & 350 & Vrms rendah, <400 Volt \\
\hline
\end{tabular}

\subsection{Perancangan Pembebanan}

Beban yang digunakan merupakan beban resistif sebesar $6 \mathrm{~kW}$. Skema peralihan daya dilakukan menggunakan breaker. Dalam hal ini, breaker berfungsi dalam mengatur waktu penambahan dan pelepasan daya. Pemodelan beban dapat dilihat pada gambar 2 .
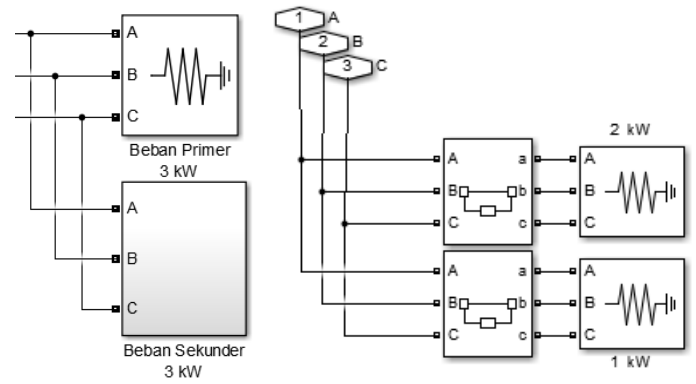

Gambar 2. (a) Pemodelan Beban Primer dan Sekunder (b) Subsistem dari Beban Sekunder

Daya aktif terbagi menjadi dua, yaitu daya utama sebesar $3 \mathrm{~kW}$ yang merupakan daya permanen dan tidak boleh dilepas dari sistem, serta $3 \mathrm{~kW}$ menjadi daya yang berubah-ubah. Daya yang berubah-ubah ini terhubung dengan breaker yang sudah diatur waktu untuk pelepasan dan penambahan dayanya. Skema pengurangan dan penambahan daya dalam 
pengujian sistem terjadi di detik ke-5 dan ke-10. Pelepasan daya terjadi pada detik ke-5 sebesar $3 \mathrm{~kW}$ dan kemudian pada detik ke-10 terjadi penambahan daya sebesar $2 \mathrm{~kW}$.

\subsection{Perancangan ELC}

Electronic Load Controller merupakan suatu alat kontrol yang dipakai dengan tujuan untuk melepaskan sisa daya listrik yang dihasilkan oleh generator. Prinsip dasar ELC adalah daya listrik pada generator harus konstan meskipun beban konsumen dapat bervariasi dengan cara yang tidak bisa dipresiksi dari nol hingga nilai beban penuh dari sistem. Apabila terjadi perubahan beban konsumen, beban ballast disesuaikan sehingga total beban pada generator tetap konstan seperti [10]:

$$
P_{\text {out }}=P_{c}+P_{d}
$$

Di mana :

$P_{\text {out }}=$ Daya output generator

$P_{c} \quad=$ Daya beban konsumen

$P_{\mathbb{d}}=$ Dump Load Power

Electronic Load Controller (ELC) yang digunakan telah ditunjukkan dalam gambar 3.

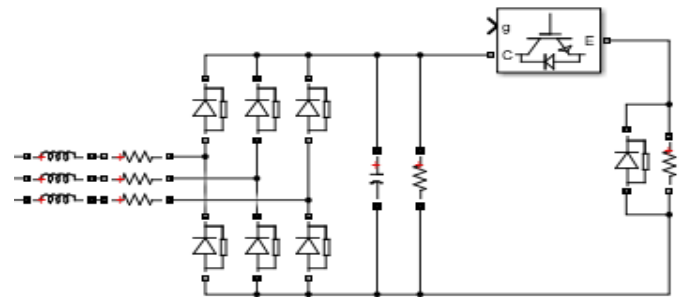

Gambar 3. Rangkaian Electronic Load Controller (ELC)

Seperti yang ditunjukkan pada gambar 3, ELC yang digunakan terdiri dari jembatan penyearah diode yang tidak terkontrol, sirkuit kontrol dan juga saklar solid-state (IGBT) yang beroperasi sebagai chopper [11]. Tegangan keluaran generator diumpankan ke sirkuit ELC yang terdiri dari diode rectifier melalui nilai induktansi sumber yang kecil dan resistansi. Terdapat kapasitor penyaring dihubungkan di output rectifier untuk menyaring riak dari tegangan dc.

\subsection{Perancangan PID-GA}

Pada sistem kontrol PID ada tiga jenis aksi kontrol, diantaranya yaitu aksi kontrol proporsional, integral dan derivative dimana masing-masing memiliki keunggulan tersendiri. Seperti kontrol proporsional memiliki keunggulan rise time yang cepat, integral unggul dalam memperkecil error dan keunggulan dari kontrol derivative adalah meredam error atau overshoot/undershoot [12]. Kontrol PID digunakan untuk mempertahankan nilai nominal tegangan generator saat terjadi perubahan penggunaan daya konsumen. Gambar 4 merupakan pemodelan kontroler PID.

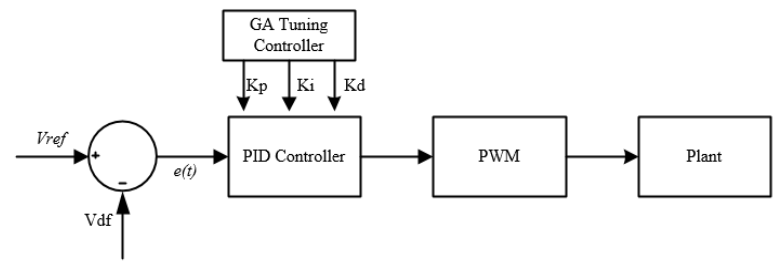

Gambar 4. Blok Diagram Konsep Pengontrolan menggunakan PID

Fluktasi tegangan akibat adanya perubahan penggunaan daya pada konsumen ditangani kontroler PID dinilai cukup berpengaruh. Nilai parameter PID, $K_{p}=2, K_{i}=0,3$ dan $K_{d}=0,5$ ditentukan dengan metode trial and error.

Penelitian ini algoritma genetika akan dipakai dalam menentukan nilai PID. Tujuan dari penentuan nilai parameter $\mathrm{K}_{\mathrm{p}}, \mathrm{K}_{\mathrm{i}}$ dan $\mathrm{K}_{\mathrm{d}}$ ini adalah untuk mengeluarkan hasil pengontrolan yang 
maksimal [13]. Performa dari perancangan sistem kontrol yang bagus sangat bergantung dari seberapa baik dalam menentukan parameter awalnya. Tabel 3 merupakan parameter awal dari algoritma genetika.

Tabel 3. Parameter GA

\begin{tabular}{|c|c|}
\hline Parameter & Nilai \\
\hline Population size & 30 \\
\hline Initial range & {$[0 ; 10]$} \\
\hline Selection & Tournament \\
\hline Mutation & Uniform \\
\hline Crossover function & Scattered \\
\hline Generation & 50 \\
\hline Stall Generation & 5 \\
\hline
\end{tabular}

Perhitungan nilai fitness dari setiap kromosom sebagai pemilah fungsi objektif adalah suatu hal yang sangat vital. ITAE digunakan untuk menghitung indeks performa pada kontroler yang didefenisikan dalam Persamaan 4 [8].

$$
\text { ITAE }=\int_{0}^{T} t \cdot|r(t)-y(t)| d t
$$

Dimana:

$$
\begin{aligned}
& r(t)=\text { input referensi } \\
& y(t)=\text { variable terukur }
\end{aligned}
$$

\section{HASIL DAN PEMBAHASAN}

\subsection{Pengujian Tanpa ELC Dengan Beban Konstan dan Berubah}

Hasil tegangan output dari pengujian sistem dasar Self-Excited Induction Generator menggunakan beban resistif konstan sebesar 6000 watt dengan konfigurasi star tanpa ELC dapat dilihat dalam Gambar 5.

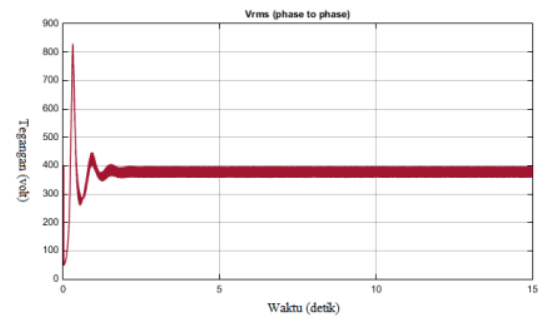

Gambar 5. Tegangan Output Sistem SEIG tanpa ELC dengan Beban Konsumen Konstan

Gambar 5 tersebut menunjukkan hasil dari pengujian sistem dasar dapat menghasilkan tegangan output generator senilai 395,5 V. Hal ini disebabkan oleh kinerja generator yang stabil sehingga bisa mempertahankan tegangan sistem. Kemudian, hasil dari pengujian sistem dasar SEIG tanpa dilengkapi dengan ELC ketika diuji dengan perubahan pada beban dapat dilihat dalam Gambar 6.

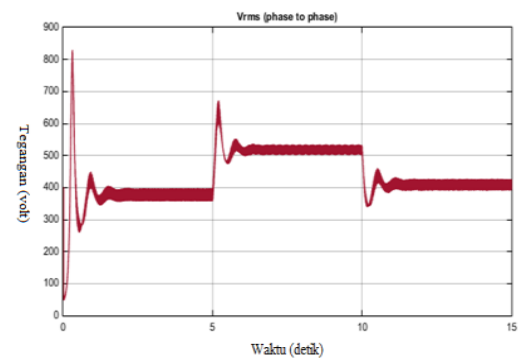

Gambar 6. Tegangan Output Sistem SEIG tanpa ELC dengan Beban Konsumen Berubah-ubah 
Terlihat dalam Gambar 6 perubahan penggunaan daya beban konsumen mengakibatkan terjadinya fluktuasi tegangan. Ketika ada penurunan penggunaan daya beban pada detik ke-5 sebesar 50\%, tegangan keluaran SEIG mengalami kenaikan dari yang sebelumnya 395,5 V menjadi 504,7 V. Selanjutnya, pada detik ke-10 ketika peningkatan daya beban sebesar $2 \mathrm{~kW}$ terjadi setelah adanya penurunan, respon tegangan keluaran generator turun menjadi 394,5 V.

\subsection{Pengujian ELC Terkontrol PID}

Dalam pengujiannya perubahan daya beban konsumen dilakukan dua tahap perubahan. Tahap pertama terjadi penuruan sebesar 50\% dan yang kedua mengalami kenaikan sebesar 2 kW. Gambar 7 merupakan hasil pengujian sistem SEIG dengan kontrol PID pada ELC.

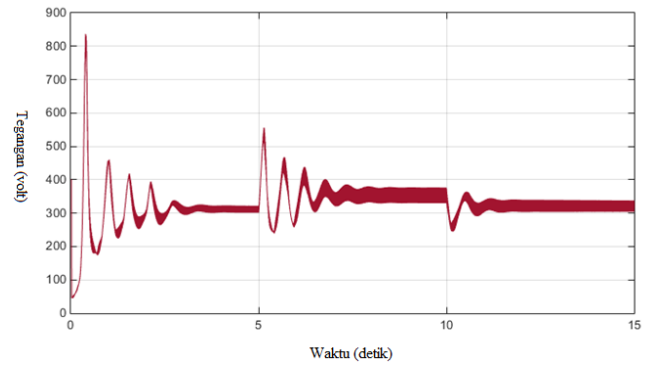

Gambar 7. Tegangan Keluaran saat Beban Konsumen Berubah-ubah dengan ELC terkontrol PID

Nilai parameter PID yang digunakan telah ditentukan dengan metode trial and error. Nilai $\mathrm{K}_{\mathrm{p}}, \mathrm{K}_{\mathrm{i}_{\mathrm{a}}}$ dan $\mathrm{K}_{\mathrm{d}}$ masing-masing sebesar 2, 0.3 dan 0.5. Dari Gambar 7 tersebut dapat dilihat bahwa pada saat terjadi penurunan penggunaan daya konsumen pada detik ke-5 terlihat bahwa tegangan yang dihasilkan sebesar $332 \mathrm{~V}$. Selanjutnya setelah terjadi penurunan, pada detik ke10 daya konsumen mengalami kenaikan sebesar $2 \mathrm{~kW}$ tegangan keluaran generator turun menjadi 318 V. Ketika terjadi perubahan pada beban terlihat tegangan keluaran generator tidak stabil karna melewati standar ketentuan yang telah ditetapkan untuk tegangan yaitu sebesar $10 \%$. Tabel 4 menunjukkan respon transien tegangan keluaran generator ketika menggunakan ELC dengan kontrol PID.

Tabel 4. ELC Terkontrol PID dengan Beban Berubah

\begin{tabular}{|l|l|l|l|}
\hline \multicolumn{1}{|c|}{ Parameter } & \multicolumn{1}{c|}{ Nilai start awal } & \multicolumn{1}{c|}{ Nilai detik ke-5 } & \multicolumn{1}{c|}{ Nilai detik ke-10 } \\
\hline Rise Time $(\mathrm{s})$ & $4.5103 \mathrm{e}-17$ & 0.015 & 0.017 \\
\hline Settling Time $(\mathrm{s})$ & 4.996 & 9.999 & 14.999 \\
\hline Overshoot $(\%)$ & 173.090 & 67.707 & 17.614 \\
\hline Peak $(\mathrm{rad} / \mathrm{s})$ & 836.678 & 556.248 & 372.247 \\
\hline Peak Time $(\mathrm{s})$ & 0.394 & 5.147 & 10.005 \\
\hline
\end{tabular}

Berdasarkan sinyal yang didapat dalam Gambar 7 ketika beban $6 \mathrm{~kW}$ diambil sampel untuk analisa FFT sebanyak 200 siklus yang dimulai dari detik ke 0 dengan frekuensi fundamental $50 \mathrm{~Hz}$ dan maksimum frekuensi $500 \mathrm{~Hz}$ ditunjukkan Gambar 8. Mengacu pada Gambar 9 diketahui THD yang dihasilkan sebesar $48,11 \%$.

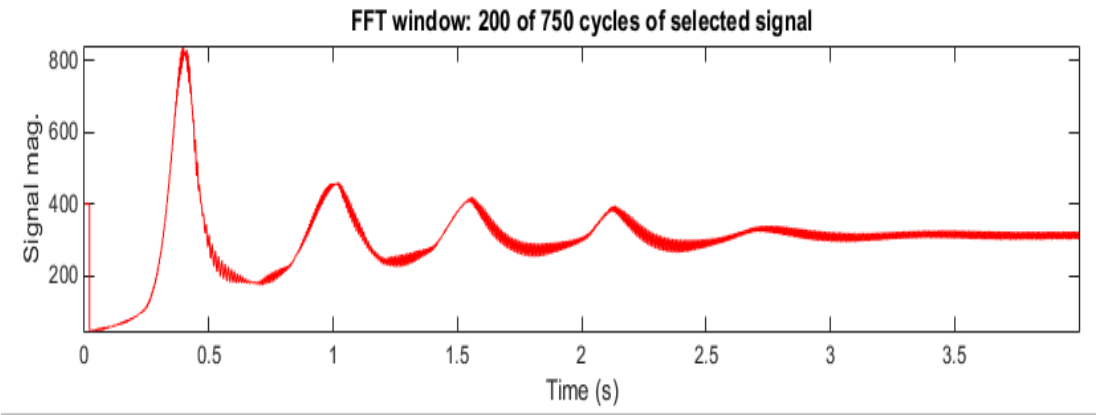

Gambar 8. Grafik Magnituda Sinyal Tegangan Beban 6 kW dengan Kontrol PID

IJEIS Vol. 10, No. 1, April 2020: $41-52$ 


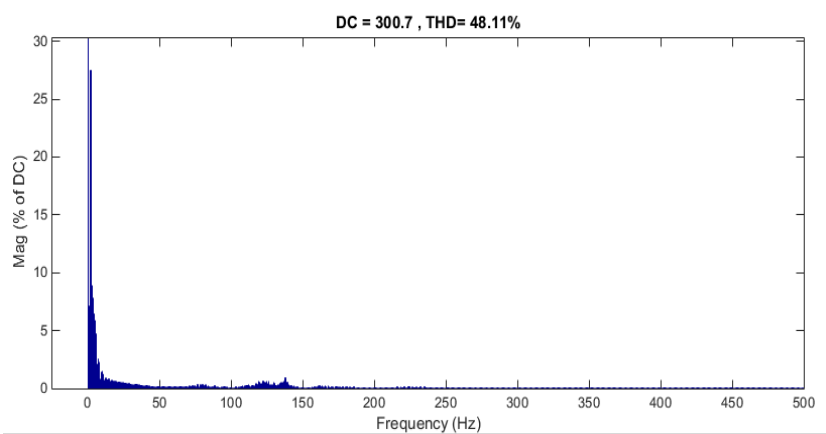

Gambar 9. Spektrum THD dari Sinyal Tegangan Beban 6 kW dengan Kontrol PID

Kemudian ketika beban $3 \mathrm{~kW}$, seperti yang ditunjukkan Gambar 10 diambil sampel untuk analisa FFT sebanyak 200 siklus yang dimulai dari detik ke 5 dengan frekuensi fundamental dan maksimum frekuensi yang sama. Mengacu pada Gambar 11 diketahui THD sebesar $18,59 \%$.

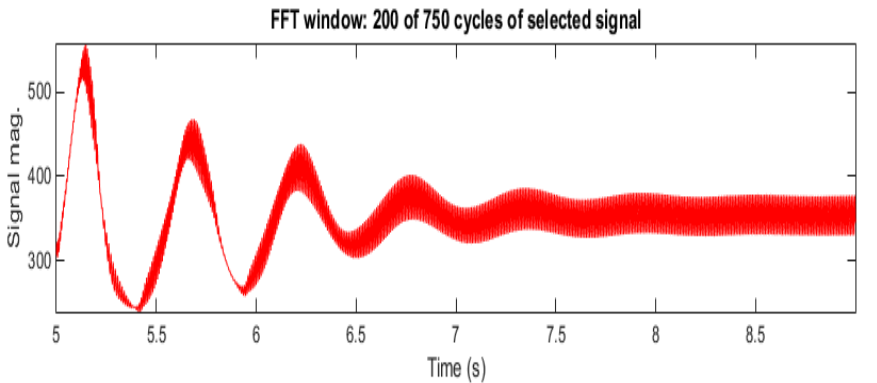

Gambar 10. Grafik Magnituda Sinyal Tegangan Beban 3 kW dengan Kontrol PID

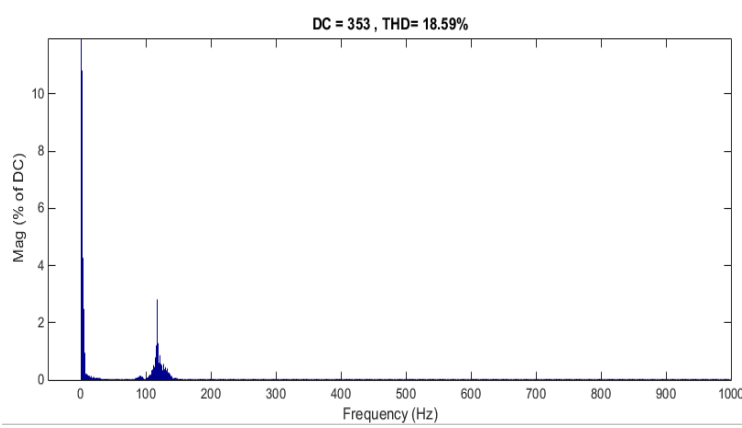

Gambar 11. Spektrum THD dari Sinyal Tegangan Beban 3 kW dengan Kontrol PID

Selanjutnya ketika beban $3 \mathrm{~kW}$ diambil sampel untuk analisa FFT sebanyak 200 siklus yang dimulai dari detik ke 10 dengan frekuensi fundamental dan maksimum frekuensi yang sama ditunjukkan oleh Gambar 12. Mengacu pada Gambar 13 diketahui THD sebesar 8,10\%.

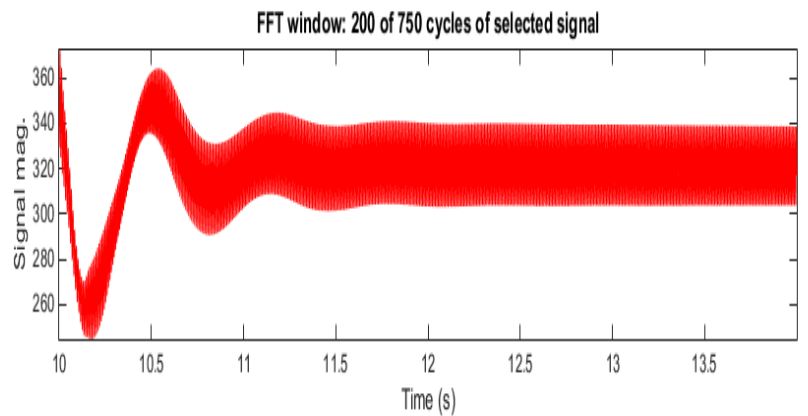

Gambar 12. Grafik Magnituda Sinyal Tegangan Beban 5 kW dengan Kontrol PID 


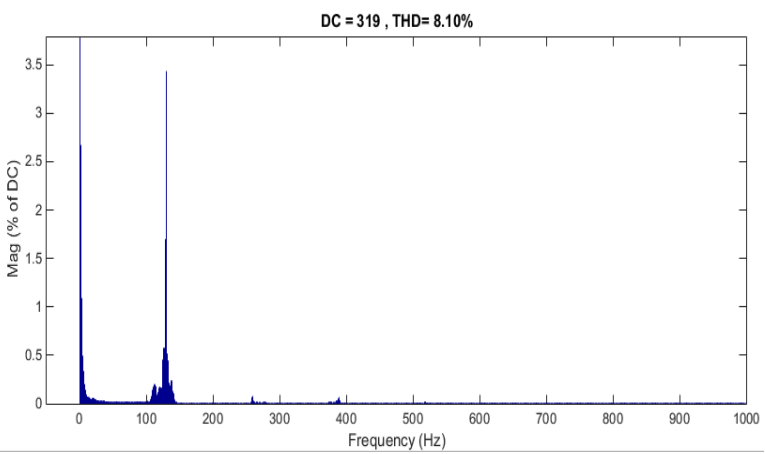

Gambar 13. Spektrum THD dari Sinyal Tegangan Beban 5 kW dengan Kontrol PID

\subsection{Pengujian ELC Terkontrol PID-GA}

Pada hasil pengujian sistem SEIG menggunakan ELC terkontrol PID dengan optimalisasi berbasis algoritma genetika, didapat ditunjukan pada Gambar 14.

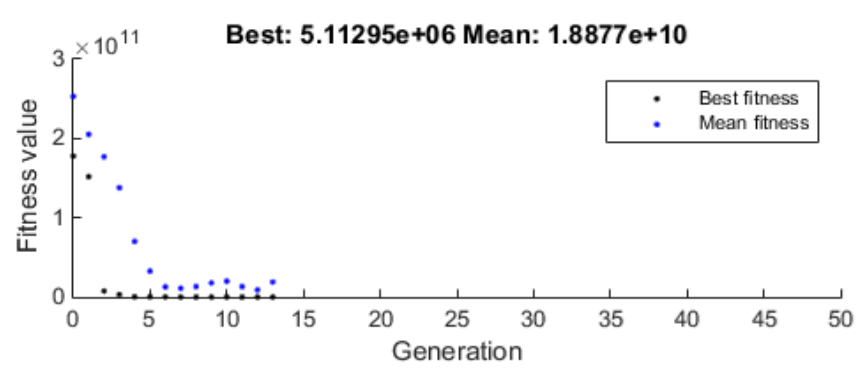

Gambar 14. Grafik Nilai Mean Fitness dan Best Fitness

Dalam Gambar 14, best fitness merupakan plot yang menunjukkan nilai fitness terbaik di setiap generasi dan mean fitness merupakan plot individu dengan nilai fungsi fitness terbaik di setiap generasi. Dalam bab sebelumnya telah dijelaskan pengaturan algoritma genetika di optimtool MATLAB. Terlihat digambar 14 optimasi dihentikan pada iterasi ke 13, ini dikarenakan rata-rata perubahan nilai fitness kurang dari function tolerance.

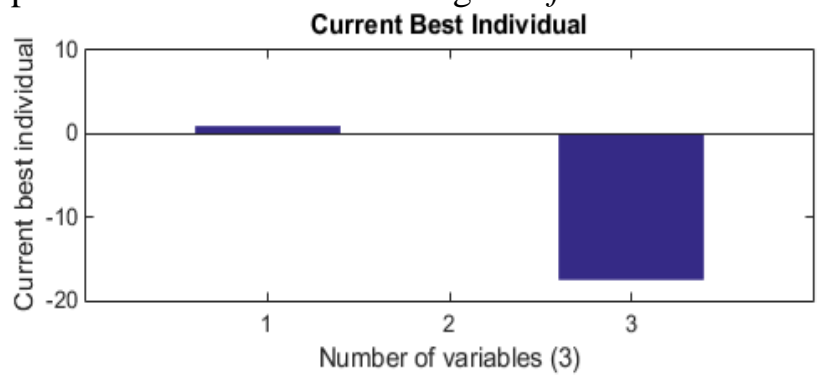

Gambar 15. Parameter Nilai $K_{p}, K_{d}$ dan $K_{\mathrm{i}}$ dengan Optimasi GA

Gambar 15 akan diperjelas dengan Tabel 5, di mana merupakan nilai PID terbaik yang didapat setelah dioptimasi menggunakan algoritma genetika.

Tabel 5. Nilai Parameter PID dengan Optimasi GA

\begin{tabular}{|c|c|c|}
\hline $\mathbf{K}_{\mathbf{p}}$ & $\mathbf{K}_{\mathbf{1}}$ & $\mathbf{K}_{\mathbf{d}}$ \\
\hline 0.93 & -17.507 & 0.082 \\
\hline
\end{tabular}

Gambar 16 merupakan hasil pengujian sistem SEIG menggunakan nilai PID yang didapatkan melalui optimalisasi dengan algoritma genetika.

IJEIS Vol. 10, No. 1, April 2020: $41-52$ 


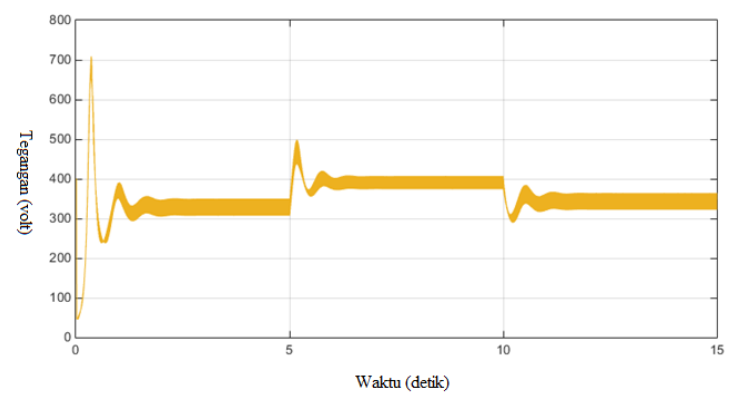

Gambar 16. Tegangan Keluaran saat Beban Konsumen Berubah-ubah dengan ELC Terkontrol PID-GA

Dalam gambar 16 tersebut terlihat saat terjadi penurunan penggunaan daya beban konsumen pada detik ke-5 tegangan yang dihasilkan senilai 403,5 V. Kemudian pada detik ke10 mengalami kenaikan penggunaan daya beban konsumen sebesar $2 \mathrm{~kW}$ tegangan keluaran yang dihasilkan senilai $363 \mathrm{~V}$. Tegangan yang dihasilkan cukup stabil karena masih pada range yang diizinkan.

Tabel 6. ELC Terkontrol PID-GA pada Beban Berubah

\begin{tabular}{|c|c|c|c|}
\hline Parameter & Nilai start awal & Nilai detik ke-5 & Nilai detik ke-10 \\
\hline Rise Time $(s)$ & $2.7756 \mathrm{e}-17$ & 0.032 & 0.012 \\
\hline Settling Time $(s)$ & 4.998 & 9.999 & 14.999 \\
\hline Overshoot $(\%)$ & 102.609 & 23.409 & 11.655 \\
\hline Peak $(\mathrm{rad} / \mathrm{s})$ & 708.864 & 498.540 & 406.011 \\
\hline Peak Time $(s)$ & 0.362 & 5.171 & 10.001 \\
\hline
\end{tabular}

Berdasarkan sinyal yang didapat dalam Gambar 16 yang merupakan hasil pengujian sistem menggunakan kontrol PID-GA, saat beban $6 \mathrm{~kW}$ diambil sampel untuk analisa FFT sebanyak 200 siklus yang dimulai dari detik ke 0 seperti yang ditunjukkan Gambar 17 dengan frekuensi fundamental $50 \mathrm{~Hz}$ dan maksimum frekuensi $500 \mathrm{~Hz}$. Mengacu pada Gambar 18 diketahui THD sebesar $35,32 \%$.

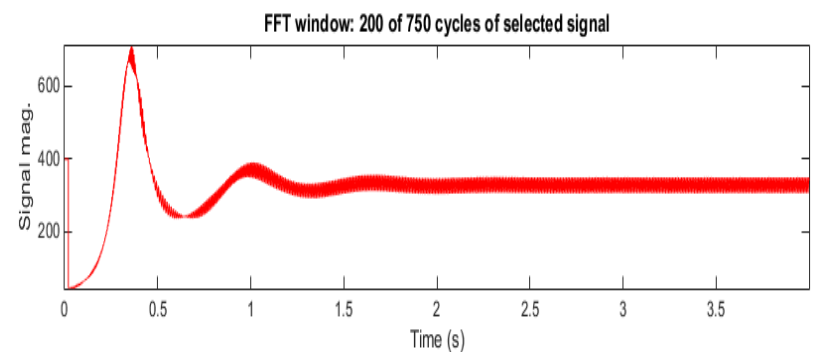

Gambar 17. Grafik Magnituda Sinyal Tegangan Beban 6 kW dengan Kontrol PID-GA

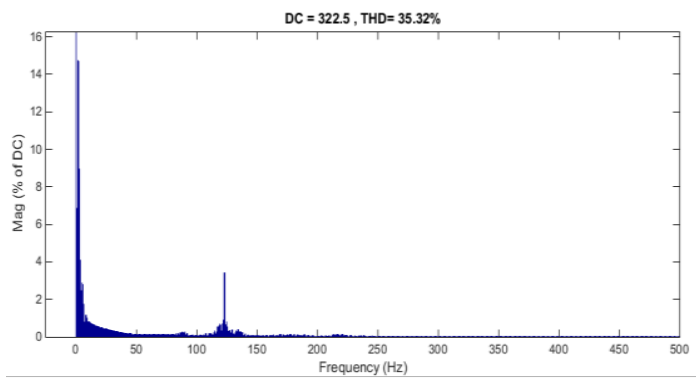

Gambar 18. Spektrum THD dari Sinyal Tegangan Beban 6 kW dengan Kontrol PID-GA

Kemudian ketika beban $3 \mathrm{~kW}$ diambil sampel untuk analisa FFT sebanyak 200 siklus seperti yang ditunjukkan Gambar 19 yang dimulai dari detik ke 5 dengan frekuensi fundamental 
$50 \mathrm{~Hz}$ dan maksimum frekuensi $500 \mathrm{~Hz}$. Mengacu pada Gambar 20 diketahui THD sebesar $7,14 \%$.

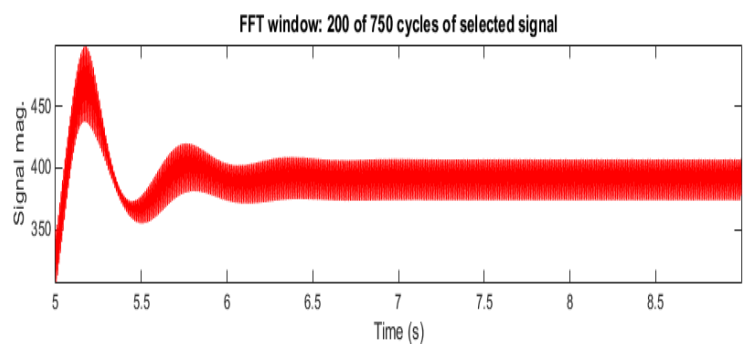

Gambar 19. Grafik Magnituda Sinyal Tegangan Beban 3 kW dengan Kontrol PID-GA

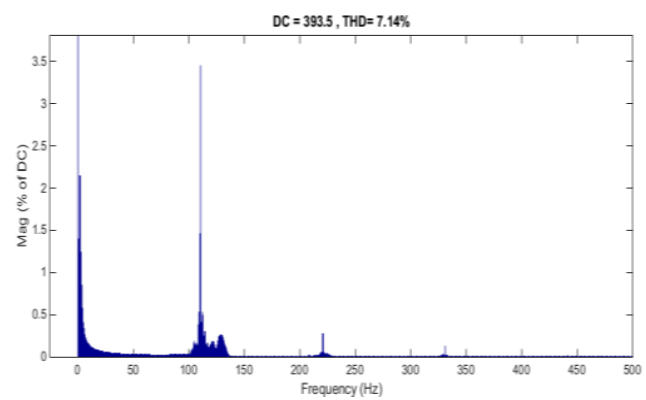

Gambar 20. Spektrum THD dari Sinyal Tegangan Beban 3 kW dengan Kontrol PID-GA

Selanjutnya ketika beban $5 \mathrm{~kW}$ diambil sampel untuk analisa FFT sebanyak 200 siklus yang dimulai dari detik ke 10 dengan frekuensi fundamental $50 \mathrm{~Hz}$ dan maksimum frekuensi $500 \mathrm{~Hz}$ ditunjukkan oleh Gambar 21. Mengacu pada Gambar 22 diketahui THD yang dihasilkan sebesar $7,23 \%$.

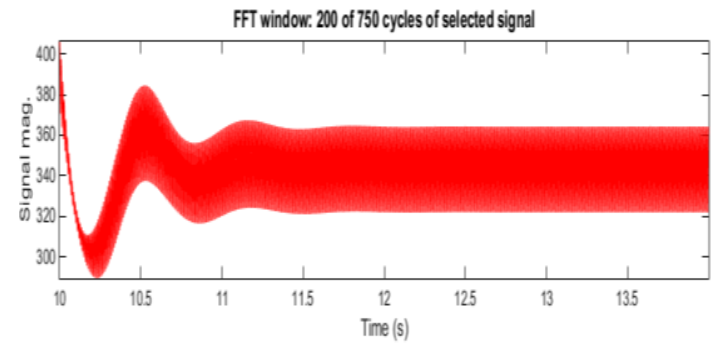

Gambar 21. Grafik Magnituda Sinyal Tegangan Beban 5 kW dengan Kontrol PID-GA

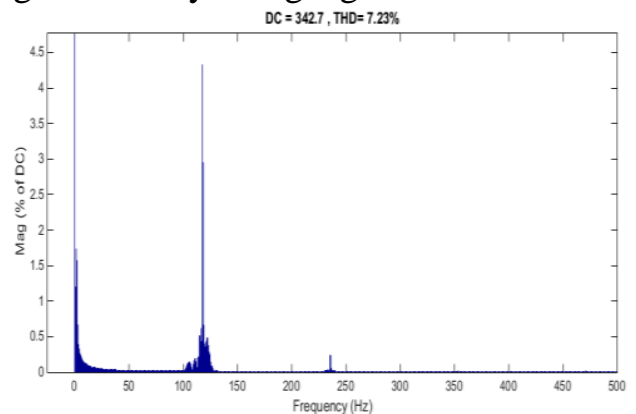

Gambar 22. Spektrum THD dari Sinyal Tegangan Beban 5 kW dengan Kontrol PID-GA

Hasil dari pengujian sistem ELC menggunakan kontrol PID dan ELC dengan kontrol PID-GA yang sudah dilakukan dibandingkan untuk mengetahui performa dari kedua kontroler. Gambar 23 merupakan perbandingan hasil sistem menggunakan ELC dengan kontrol PID dan PID-GA. 


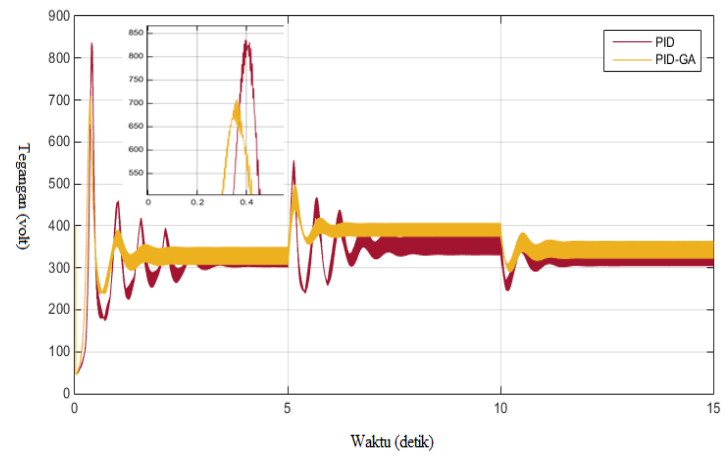

Gambar 23. Perbandingan Tegangan Keluaran saat Beban Konsumen Berubah-ubah dengan ELC terkontrol PID dan PID-GA

Dari gambar 23 yang merupakan perbandingan dari tegangan keluaran generator menggunakan ELC terkontrol PID dan PID-GA dapat dilihat bahwa keduanya menunjukkan respon yang berbeda. Terlihat bahwa pengaruh terhadap respon transien merupakan kelebihan dari optimalisasi algoritma genetika karna respon yang lebih baik ditunjukkan oleh sistem yang menggunakan PID-GA. Pada saat start awal maupun ketika terjadi perubahan beban terlihat bahwa overshoot yang dihasilkan oleh sistem dengan kontrol PID-GA lebih kecil dibandingkan dengan sistem yang menggunakan kontrol PID. Respon dari sistem yang menggunakan kontrol PID-GA juga terlihat lebih cepat dalam mencapai keadaan mantap daripada kontrol PID. Untuk dapat lebih jelas mengetahui perbandingan respon kedua kontroler tersebut dapat dilihat dalam Tabel 7.

Tabel 7. ELC Terkontrol PID dan PID-GA dengan Beban Berubah

\begin{tabular}{|c|c|c|c|c|c|c|}
\hline \multirow{2}{*}{ Param } & \multicolumn{3}{|c|}{ PID } & \multicolumn{3}{c|}{ PID-GA } \\
\cline { 2 - 7 } & $\begin{array}{c}\text { Start } \\
\text { awal }\end{array}$ & $\begin{array}{c}\text { Detik } \\
\text { ke-5 }\end{array}$ & $\begin{array}{c}\text { Detik } \\
\text { ke-10 }\end{array}$ & $\begin{array}{c}\text { Start } \\
\text { awal }\end{array}$ & $\begin{array}{c}\text { Detik } \\
\text { ke-5 }\end{array}$ & $\begin{array}{c}\text { Detik } \\
\text { ke-10 }\end{array}$ \\
\hline$T_{Y}(s)$ & $\begin{array}{c}4.5103 \\
\mathrm{e}-17\end{array}$ & 0.015 & 0.017 & $\begin{array}{c}2.7756 \\
\mathrm{e}-17\end{array}$ & 0.032 & 0.012 \\
\hline$T_{\Xi}(s)$ & 4.996 & 9.999 & 14.999 & 4.998 & 9.999 & 14.999 \\
\hline$M_{P}(\%)$ & $\begin{array}{c}173.09 \\
0\end{array}$ & 67.707 & 17.614 & $\begin{array}{c}102.60 \\
9\end{array}$ & 23.409 & 11.655 \\
\hline $\begin{array}{c}\text { Peak } \\
\text { rad/s })\end{array}$ & $\begin{array}{c}836.67 \\
8\end{array}$ & $\begin{array}{c}556.24 \\
8\end{array}$ & 372.247 & $\begin{array}{c}708.86 \\
4\end{array}$ & $\begin{array}{c}498.54 \\
0\end{array}$ & $\begin{array}{c}406.01 \\
1\end{array}$ \\
\hline $\begin{array}{c}\text { Peak } \\
\text { Time }(\mathrm{s})\end{array}$ & 0.394 & 5.147 & 10.005 & 0.362 & 5.171 & 10.001 \\
\hline ITAE & \multicolumn{3}{|c|}{$2.0669 \mathrm{e}+11$} & \multicolumn{3}{c|}{$5.1138 \mathrm{e}+06$} \\
\hline
\end{tabular}

Berdasarkan Tabel 7 di atas dapat dilihat bahwa respon sistem yang menggunakan kontrol PID yang dioptimalisasi menggunakan algoritma genetika menghasilkan nilai overshoot dan error lebih kecil dibanding yang menggunakan kontrol PID. Saat start awal sistem dengan kontrol PID berbasis GA memiliki overshoot 70\% lebih kecil dibandingkan sistem dengan kontrol PID begitu pula ketika terjadi perubahan penggunaan daya beban pada konsumen. ITAE yang dihasilkan dari pengujian dengan adanya perubahan beban juga jauh lebih kecil.

\section{KESIMPULAN}

Pada makalah ini desain sistem kontrol tegangan pada SEIG dengan PID $^{\wedge}$ GA telah diusulkan. Berdasrkan pengujian Sistem SEIG menggunakan ELC dengan kontrol PID-GA lebih baik daripada sistem dengan kontrol PID dalam menjaga agar tegangan dipertahankan $380 \mathrm{~V}$ hingga $400 \mathrm{~V}$ dengan toleransi tegangan sebesar $10 \%$ ketika terjadi perubahan penggunaan daya beban pada konsumen. Penambahan GA untuk menentukan nilai parameter PID menghasilkan respon transien yang lebih baik dengan nilai overshoot dan error dalam ITAE lebih kecil dibandingkan dengan kontrol PID. Respon dari sistem yang menggunakan kontrol PID-GA juga terlihat lebih cepat dalam mencapai keadaan mantap daripada kontrol PID. 


\section{DAFTAR PUSTAKA}

[1] F. A. Farret and M. G. Simoes, Integation of Alternative Sources of Energy. 2006.

[2] B. Singh, S. Member, S. S. Murthy, L. S. Member, and S. Gupta, "Transient Analysis of Self-Excited Induction Generator With Electronic Load Controller ( ELC ) Supplying Static and Dynamic Loads," vol. 41, no. 5, pp. 1194-1204, 2005.

[3] L. Goyal, O. M. P. Mahela, and S. Goyal, "A Survey Of Self-Excited Induction Generator Research," vol. 2, no. 1, pp. 31-40, 2013.

[4] B. Singh, S. S. Murthy, and S. Gupta, "Analysis and implementation of an electronic load controller for a self-excited induction generator."

[5] N. Setyawan, E. A. Hakim, and Z. Zulfatman, "Signature PSO: Modified Particle Swarm Optimization Dengan Fuzzy Signature Dan Implementasi Pada Optimalisasi Kendali LQR," MULTITEK Indones., vol. 13, no. 2, pp. 29-38, 2020.

[6] N. Setyawan, N. Mardiyah, K. Hidayat, and Z. Has, "Object Detection of Omnidirectional Vision Using PSO-Neural Network for Soccer Robot," in 2018 5th International Conference on Electrical Engineering, Computer Science and Informatics (EECSI), 2018, pp. 117-121.

[7] N. Setyawan, M. Nasar, and N. Mardiyah, "Jaya-Neural Network for Server Room Temperature Forecasting Through Sensor Network," in 2019 International Electronics Symposium (IES), 2019, pp. 428-431.

[8] T. O. Mahony, C. J. Downing, and K. Fatla, "Genetic algorithms for PID parameter optimisation : minimising error criteria," Process Control Instrum., pp. 26-28, 2000.

[9] R. Harahap, "Analisis Dan Simulasi Pengaturan Tegangan Generator Induksi Berpenguatan Sendiri Menggunakan Static Synchronous Compensator (STATCOM)," no. 1, pp. 83-88, 2016.

[10] A. Kumar and V. K. Sharma, "Implementation of Self Excited Induction Generator ( Seig ) With Igbt Based Electronic Load Controller ( Elc ) in Wind Energy Systems," no. Im, pp. 188-193, 2013.

[11] B. Singh, S. Member, S. S. Murthy, L. S. Member, and S. Gupta, "Analysis and Design of Electronic Load Controller for Self-Excited Induction Generators," vol. 21, no. 1, pp. 285-293, 2006.

[12] E. C. Wijaya, "Sistem Kontrol Generator Induksi Dengan Beban Komplemen Berbasis Pid Pada Pembangkit Listrik Mikrohidro,"Skripsi, Universitas Negeri Jember, 2015.

[13] E. H. Putra, Z. Has, and M. Effendy, "Robust Adaptive Sliding Mode Control Design with Genetic Algorithm for Brushless DC Motor," Proceeding Electr. Eng. Comput. Sci. Informatics, vol. 5, no. 5, pp. 330-335, 2018. 